\title{
Screw needle cytology of thyroid nodules is associated with a lower non-diagnostic rate compared to fine needle aspiration
}

\author{
Tamira K Klooker 1, ${ }^{*}$, Anne Huibers ${ }^{2, *}$, Klaas in 't Hof ${ }^{2,3}$, Els J M Nieveen van Dijkum², \\ Saffire S Phoa ${ }^{4}$, Susanne van Eeden ${ }^{5}$ and Peter H Bisschop' ${ }^{1}$ \\ Departments of ${ }^{1}$ Endocrinology and Metabolism and ${ }^{2}$ Surgery, Academic Medical Centre, Meibergdreef 9, \\ Amsterdam 1105 AZ, The Netherlands, ${ }^{3}$ Department of Surgery, Flevo Hospital, Almere, The Netherlands and \\ Departments of ${ }^{4}$ Radiology and ${ }^{5}$ Pathology, Academic Medical Centre, Amsterdam, The Netherlands \\ *(TK Klooker and A Huibers contributed equally to this work)
}

Correspondence should be addressed to $\mathrm{P}$ H Bisschop Email

p.h.bisschop@amc.uva.nl

\section{Abstract}

Background: Fine needle aspiration (FNA) cytology is the method of choice to exclude malignancy in thyroid nodules. A major limitation of thyroid FNA is the relatively high rate (13-17\%) of non-diagnostic samples. The aim of this study is to determine the diagnostic yield of a screw needle compared to the conventional FNA.

Methods: We retrospectively analysed thyroid nodule cytology of all patients that underwent thyroid nodule fine needle or screw needle aspiration between July 2007 and July 2012 in a single academic medical centre. Cytology results were categorized according to the Bethesda classification system.

Results: In total, 644 punctures of thyroid nodules from 459 patients were available for analysis. The screw needle was used 531 times, and the conventional fine needle 113 times. The percentage of non-diagnostic cytology was significantly lower in the screw needle samples than in the fine needle samples $(3 \%$ vs $17 \%, P<0.001)$.

Conclusion: This study shows a significantly better diagnostic performance of the screw needle compared to the conventional fine needle in cytology of thyroid nodules.

\section{Introduction}

Thyroid nodules are common. Approximately $6-8 \%$ of the total population has a palpable nodule, and 50\% will develop a non-palpable thyroid nodule during their lifetime (1). Thyroid nodule cytology by fine needle aspiration (FNA) is currently considered the preferred method to differentiate malignant from benign lesions (2). FNA cytology was first described in 1930 and was widely adopted in the 1980's $(3,4)$. FNA is performed ultrasound-guided with a 22-27 gauge, most frequently 25-27 gauge needle by which 2-5 aspirations of the thyroid nodule are collected (5). A major limitation of the FNA, however, is the high percentage of non-diagnostic samples. A meta-analysis describing diagnostic performance of FNA cytology of more
(C) 2015 European Society of Endocrinology Printed in Great Britain than 25000 thyroid nodules, showed a non-diagnostic rate of $13 \%$ (6). With the aim of improving the diagnostic yield of the FNA procedure, a rapid onsite evaluation of the FNA-sample by a cytopathologist was introduced. This reduced non-diagnostic samples by $44 \%$, but was especially effective in the institutes with a high percentage of non-diagnostic samples (>20\%) (7). Despite the diagnostic improvement with onsite cytopathologic evaluation of ultrasound-guided FNA, the overall non-diagnostic rate remains high, between 3 and 24\% $(8,9,10,11,12)$. Since the risk of malignancy in thyroid nodules with non-diagnostic cytopathology is $5-10 \%$, additional investigation in these nodules is still warranted $(13,14,15)$.

Published by Bioscientifica Ltd. 
In addition to the conventional fine needle technique, in our centre, the Rotex needle is used to perform thyroid punctures. This needle consists of a 21-22 gauge screw needle housed in an outer cannula by which more cells can be collected compared to a conventional hollow needle (16) and costs approximately $€ 40$ per piece. With the screw needle, cells are obtained by mechanical traction rather than by vacuum, as in conventional FNA. We hypothesized that the number of non-diagnostic cytological samples from thyroid nodules is lower when obtained with a screw needle compared to conventional FNA. Therefore, we retrospectively compared the results of cytological punctures performed with the screw needle to those performed with conventional FNA.

\section{Methods}

All patients that underwent an ultrasound-guided thyroid puncture between July 2007 and July 2012 at the Academic Medical Centre (AMC) were included in the present study. Patients were identified in PALGA, a centralized database that contains all histology and cytology reports. We retrospectively analysed radiology and cytology reports. We excluded all punctures for which the type of needle remained unknown. Radiology reports were used to assess which radiologist performed the puncture, the type of needle (screw needle or conventional fine needle), whether the nodule had cystic components, and the size of the nodule, expressed in scales of $<0.5 \mathrm{~cm}, 0.5-0.9 \mathrm{~cm}, 1.0-1.4 \mathrm{~cm}, 1.5-1.9 \mathrm{~cm}$, $2.0-2.4 \mathrm{~cm}, 2.5-2.9 \mathrm{~cm}, 3.0-3.4 \mathrm{~cm}, 3.5-3.9 \mathrm{~cm}$, $4.0-4.4 \mathrm{~cm}, 4.5-4.9 \mathrm{~cm},>5.0 \mathrm{~cm}$. The screw needle consists of a 22 gauge needle and cytology is performed as follows. Under ultrasound guidance, the cannula with central needle inside the lumen is placed into the thyroid nodule. Then the central screwing part is advanced manually, for $10-20 \mathrm{~mm}$, making a rotational movement. After this, the outer cannula is advanced to completely cover the screwing needle, also in a rotational fashion. Both needles are then withdrawn. The material obtained is cytological, but usually contains more cells compared to aspiration cytology. Generally one to two samples are needed. We do not use the available mechanical handheld device for automatic sampling.

FNA cytology is performed as follows. A 21-23 gauge needle is passed through the nodules two to three times, using a syringe to obtain a slight vacuum during passage. The sample is then examined. In general, two samples are taken. When insufficient material is obtained a screw needle is chosen for a third sampling. All samples of the screw needle and fine needle were examined by an in-room pathology technician. Resampling was performed immediately if obtained material seemed insufficient. Usually no anaesthetics are used. Cytology samples from the screw needle and from the fine needle were processed in the same way, using a routine procedure by which one or two slides were made and an air dried Giemsa stain was used. Final diagnosis was made by the pathologist clinically scheduled for cytology. Cytology results were classified according to the international Bethesda classification (17): Bethesda I, non-diagnostic or unsatisfactory; Bethesda II, benign; Bethesda III, atypia of undetermined significance/follicular lesion of undetermined significance; Bethesda IV, follicular neoplasm/'suspicious' for follicular neoplasm; Bethesda V, suspicious for malignancy; Bethesda VI, malignant. Statistical analysis was performed using commercially available software (SPSS), IBM version 22, 2013. Continuous data were compared using the Student's $t$-test and nominal data were compared by the Mann-Whitney $U$ test. Comparison of proportion was performed using $\chi^{2}$ testing. Differences were considered significant at the 5\% level.

\section{Results}

A total of 861 punctures in 589 patients were performed between July 2007 and July 2012. After excluding the nodules of which it was unknown what kind of needle was used ( $n=217), 644$ nodules in 459 patients were available for further analysis. Baseline characteristics of the excluded patients ( $80 \%$ female, mean age $47 \pm 15$ years and median nodule size of $2.5-3.0 \mathrm{~cm}$ ) were comparable to those of the included patients (75\% female, mean age $49 \pm$ 15 years and median nodule size of $2.5-3.0 \mathrm{~cm}$ ). The screw needle was used in 531 (82\%) nodules, and conventional FNA in $113(18 \%)$ nodules. Baseline characteristics of patients that underwent a FNA were comparable to those where a screw needle was used, except for the percentage of cystic nodules, which was higher in the fine needle group (Table 1). Representative examples of a cytology sample obtained by the fine needle and screw needle are shown in Fig. 1.

The percentage of non-diagnostic samples (Bethesda I) was significantly lower in the screw needle group compared to the fine needle (3\% vs $17 \%, P<0.001$ ). There were no significant differences within the remaining Bethesda categories (Table 2). Of all samples derived from cystic nodules, 5\% (9/198) was non-diagnostic with the screw needle, vs $11 \%(8 / 68)$ with the fine needle $(P=0.066)$. The non-diagnostic rate of the solid nodules 
Table 1 Baseline characteristics.

\begin{tabular}{|c|c|c|c|}
\hline Characteristics & $\begin{array}{c}\text { Screw needle } \\
(n=531)\end{array}$ & $\begin{array}{l}\text { Fine needle } \\
\quad(n=113)\end{array}$ & $\boldsymbol{P}$ \\
\hline Mean age (years \pm s.D.) & $50 \pm 15$ & $47 \pm 15$ & 0.17 \\
\hline Female & $75 \%$ & $75 \%$ & 0.89 \\
\hline Median nodule size $(\mathrm{cm})$ & 3.3 & 2.8 & 0.73 \\
\hline Nodule $<1 \mathrm{~cm} \mathrm{( \% )}$ & $7.2 \%$ & $8.0 \%$ & 0.71 \\
\hline Nodule $>5 \mathrm{~cm} \mathrm{( \% )}$ & $11.7 \%$ & $10.6 \%$ & 0.75 \\
\hline Cystic nodule & $37 \%$ & $67 \%$ & $<0.001$ \\
\hline
\end{tabular}

was $2 \%(7 / 333)$ with the screw needle and $30 \%(11 / 37)$ with the fine needle $(P<0.001)$. Of all non-diagnostic samples with the screw needle, 15 out of 16 samples (94\%) were true insufficient and one sample was cystic fluid. With the fine needle, 16 out of 19 samples (84\%) were true insufficient and three were cystic fluid.

One dedicated radiologist performed 50.5\% $(n=325)$ of all punctures and 37 radiologists performed the remaining 319 punctures. The median number of punctures of these 37 radiologists was six punctures per radiologist during the five years of inclusion, with a range from one to 23 punctures.

The dedicated radiologist performed 281 screw needle punctures and 44 fine needle punctures. For the dedicated radiologist, the percentage of non-diagnostic punctures was $2 \%(5 / 281)$ with the screw needle and $5 \%$ with the fine needle $(2 / 44)(P=0.24)$. The remaining 37 radiologists performed 250 screw needle and 69 conventional FNA punctures. For the group of 37 radiologists, the percentage of non-diagnostic punctures was significantly lower with the screw needle compared to the fine needle, $4 \%(11 / 250)$ vs $25 \%(17 / 69)$ respectively $(P<0.001)$.

Samples were assessed by 15 pathologists all routinely involved in clinical cytology. Of these, three dedicated pathologists performed more than 120 sample analyses each, together covering 493 samples (77\%). The remaining 12 pathologists analysed 151 samples. The percentage of non-diagnostics in dedicated pathologists was 3\% $(10 / 406)$ with the screw needle, compared to $15 \%$ $(13 / 87)$ with the fine needle $(P=0.002)$. The percentage of non-diagnostics of the remaining pathologists was $5 \%$ $(6 / 125)$ with the screw needle, and $23 \%(6 / 26)$ with the fine needle $(P<0.001)$.

Finally, 102 patients $(24 \%)$ of the screw needle and 17 patients $(16 \%)$ of the fine needle group had a (hemi) thyroidectomy $(P=0.078)$. Although this difference was not statistically significant, the tendency towards a lower surgery rate within the fine needle group is explained by the higher percentage of cystic nodules in this group. Of the patients with a solid nodule within the fine needle group,
$23 \%$ underwent surgery, compared to $14 \%$ of patients with a cystic nodule. The histology of the resections is described in Table 3. Eight patients with Bethesda 5 and 6 did not undergo thyroidectomy due to comorbidity $(n=3)$, an already diagnosed lymphoma $(n=3)$ or the persistent wish of the patient not to have surgery $(n=2)$. Of all patients that underwent a screw needle puncture, 5.3\% had a proven thyroid carcinoma which was comparable to the $5.8 \%$ that was found in the fine needle group.

\section{Discussion}

In the present study, we demonstrate that the use of a screw needle in the cytologic evaluation of thyroid nodules is
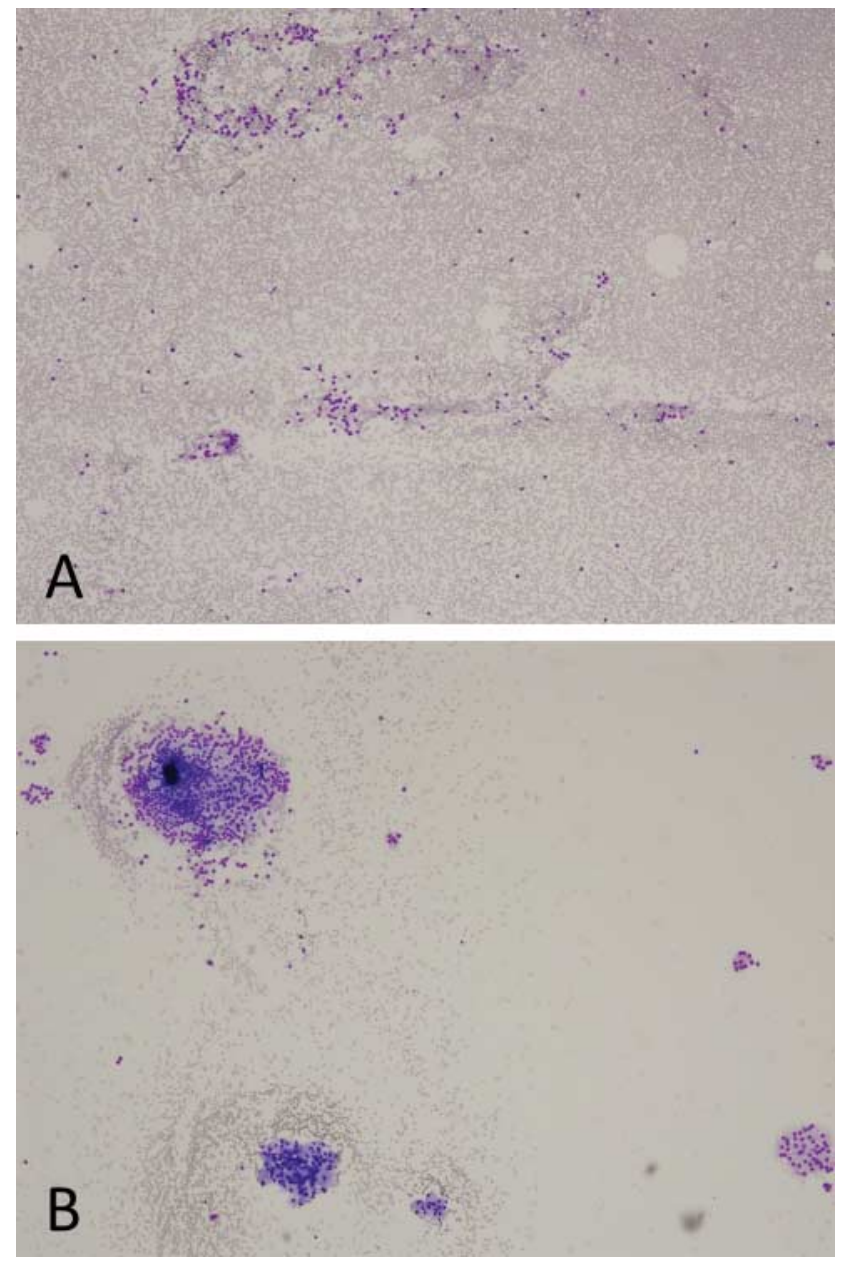

\section{Figure 1}

Representative examples of a cytology sample obtained by (A) fine needle and by (B) screw needle. Notice that the screw needle sample contains more cells but less erythrocytes (4×, Olympus BX51). $254 \times 190 \mathrm{~mm}(96 \times 96 \mathrm{DPI})$. 
Table 2 Cytological Classification.

\begin{tabular}{|c|c|c|c|}
\hline Bethesda & $\begin{array}{c}\text { Screw needle } \\
\begin{array}{c}n=531 \\
\%(n)\end{array}\end{array}$ & $\begin{array}{c}\text { Fine needle } \\
n=113 \\
\%(n)\end{array}$ & $\boldsymbol{P}$ \\
\hline I. Non-diagnostic & $3(16)$ & 17 (19) & $<0.001$ \\
\hline II. Benign & 76 (406) & $75(85)$ & 0.87 \\
\hline $\begin{array}{l}\text { III. Follicular lesion of } \\
\text { indeterminate } \\
\text { significance atypia of } \\
\text { undetermined } \\
\text { significance }\end{array}$ & $10(53)$ & $4(5)$ & 0.09 \\
\hline $\begin{array}{l}\text { IV. Suspicious for } \\
\text { follicular neoplasm }\end{array}$ & $3(16)$ & 0 & 0.13 \\
\hline $\begin{array}{l}\text { V. Suspicious for } \\
\text { malignancy }\end{array}$ & 4 (19) & $3(3)$ & 0.84 \\
\hline VI. Malignant & $4(21)$ & $1(1)$ & 0.18 \\
\hline
\end{tabular}

associated with a lower percentage of non-diagnostic samples compared to the conventional FNA. Today, FNA is the most important step in the workup of a thyroid nodule. This technique is limited, however, by the relatively high frequency of non-diagnostic samples due to the collection of insufficient material. When cytology is non-diagnostic a repeated FNA is recommended. Of the repeated samples, $\sim 40 \%$ will be non-diagnostic again and, following the guidelines, the next step would be a diagnostic (hemi) thyroidectomy $(15,18,19)$. To reduce the necessity of repeated FNAs and, more importantly, to prevent unnecessary surgery of non-malignant nodules, new techniques to improve the diagnostic yield of thyroid cytology are warranted. The FNA mainly utilizes vacuum to aspirate cells and, to a lesser extent, cells could also be obtained mechanically. With a screw needle, samples are taken by mechanical traction only, thereby providing more material. Hence we speculated that the diagnostic performance would be better with the screw needle. We showed that by using a screw needle the percentage of non-diagnostic samples was lower when compared to the conventional fine needle, endorsing that the screw needle is indeed superior in the diagnostic process of the thyroid nodule.

The most remarkable finding of this study, however, is that the largest benefit of the screw needle seems to be for the less specialized radiologists. Previously it has been shown that the experience of the radiologist is an important beneficial factor in the accuracy of thyroid cytology (20). Likewise, our data show that one dedicated radiologist, single handedly responsible for 50 percent of all punctures, had the lowest non-diagnostic rate. By using the screw needle, the non-diagnostic rate of the remaining radiologists was as low as the dedicated radiologist, irrespective of their experience.
A limitation of this study is that the amount of passes and punctures during each session and side effects were not routinely scored. Although in our experience the screw needle was very well tolerated, we do not have structured data to support this.

All punctures were performed ultra-sound guided and with the presence of a pathology technician that performed a rapid onsite evaluation of the sample. Inherent to the retrospective nature of our analysis, however, there is a risk of selection bias, especially since we were not informed about the decision of the radiologist to choose for a screw or a fine needle. We speculated that the fine needle might be used more often in cystic nodules to aspirate fluid. Indeed, in case of a pure cystic nodule, radiologists in our center tended to perform a FNA rather than a screw needle puncture. Although the screw needle lacks the vacuum to aspirate fluid, cytology samples taken of cystic nodules were still more sufficient with the screw needle than with fine needle, which is most likely related to sampling from the wall of the cyst. The lower rate of solid nodules, however, did not explain the higher percentage of non-diagnostics in the fine needle group. In contrast, samples of solid nodules were non-diagnostic in $2 \%$ of the screw needle and $30 \%$ with the fine needle. Furthermore, the percentage of non-diagnostic samples found within the fine needle group of $17 \%$ is comparable to the reported percentage in literature (6), while the $3 \%$ non-diagnostic rate with the screw needle is much lower.

A pitfall of the screw needle, however, was that there more often tended to be a Bethesda III (atypia of

Table 3 Histology. The number of patients and percentage of malignancy found in these patients that underwent a (hemi) thyroidectomy. In parenthesis are the total number of patients that were categorized following the Bethesda classification derived from the cytology samples. The total number of included patients was 459, of which 62 were scored twice in this table due to a repeated puncture with a different Bethesda classification or type of needle. Follicular adenomas were seen in six of $11(55 \%)$ nodules classified as Bethesda IV.

\begin{tabular}{|c|c|c|c|c|}
\hline \multirow[b]{2}{*}{ Cytology } & \multicolumn{2}{|c|}{ Screw needle } & \multicolumn{2}{|c|}{ Fine needle } \\
\hline & $\begin{array}{c}n \text { pts (total } n \\
\text { of pts) }\end{array}$ & Malignancy & $\begin{array}{c}n \text { pts (total } n \\
\text { of pts) }\end{array}$ & Malignancy \\
\hline Bethesda I & $1(15)$ & 0 & $1(17)$ & 0 \\
\hline Bethesda II & $44(311)$ & $3(7 \%)$ & $10(78)$ & $1(10 \%)$ \\
\hline Bethesda III & $19(42)$ & $2(11 \%)$ & $2(5)$ & $1(50 \%)$ \\
\hline Bethesda IV & $11(14)$ & $2(18 \%)$ & 0 & - \\
\hline Bethesda V & 13 (16) & $9(69 \%)$ & $3(3)$ & $3(100 \%)$ \\
\hline Bethesda VI & 14 (19) & $14(100 \%)$ & $1(1)$ & $1(100 \%)$ \\
\hline
\end{tabular}


undetermined significance/follicular lesion of undetermined significance). Samples taken with the screw needle mostly consist of more cells and although we can only speculate, we believe that the higher number of cells could be one of the explanations of a possible higher rate of Bethesda III.

Nevertheless, histology data show that the predictive value of malignancy by the Bethesda classification with the screw needle is similar to the expected percentages shown in previous studies (17), indicating that the screw needle also has a good performance in the other Bethesda categories.

Finally, the screw needle is listed for approximately $€ 40$. The number needed to puncture with the screw needle to avoid one non diagnostic sample is seven punctures $(1 /(0.17-0.03))$, which accumulates to $€ 280(7 \times € 40)$. The cost of an ultrasound guided puncture and cytology at our centre is $€ 325$. Therefore, the cost-benefit analysis is slightly positive at our centre. Nevertheless, the costs of the ultrasound guided puncture and cytology will vary between different centres and countries. Therefore, each centre should make an individualized cost-benefit analysis.

In conclusion, the current study indicates that the screw needle is a promising tool in the diagnostics of thyroid nodules. Additional prospective investigation is needed to confirm these results.

\section{Declaration of interest}

The authors declare that there is no conflict of interest that could be perceived as prejudicing the impartiality of the research reported.

\section{Funding}

This research did not receive any specific grant from any funding agency in the public, commercial or not-for-profit sector.

\section{References}

1 Dean DS \& Gharib H. Epidemiology of thyroid nodules. Best Practice \& Research. Clinical Endocrinology \& Metabolism 200822 901-911. (doi:10.1016/j.beem.2008.09.019)

2 Pacini F, Castagna MG, Brilli L \& Pentheroudakis G. Thyroid cancer: ESMO Clinical Practice Guidelines for diagnosis, treatment and follow-up. Annals of Oncology 201223 (Suppl 7) vii110-vii119. (doi:10.1093/annonc/mds230)

3 Martin HE \& Ellis EB. Biopsy by needle puncture and aspiration. Annals of Surgery 193092 169-181. (doi:10.1097/00000658-193008000-00002)

4 Sakorafas GH. Thyroid nodules; interpretation and importance of fine-needle aspiration (FNA) for the clinician - practical considerations.
Surgical Oncology 201019 e130-e139. (doi:10.1016/j.suronc.2010. 06.003)

5 Layfield LJ, Cibas ES, Gharib H \& Mandel SJ. Thyroid aspiration cytology: current status. CA: A Cancer Journal for Clinicians 200959 99-110. (doi:10.3322/caac.20014)

6 Bongiovanni M, Spitale A, Faquin WC, Mazzucchelli L \& Baloch ZW The Bethesda system for reporting thyroid cytopathology: a metaanalysis. Acta Cytologica 201256 333-339. (doi:10.1159/000339959)

7 Witt BL \& Schmidt RL. Rapid onsite evaluation improves the adequacy of fine-needle aspiration for thyroid lesions: a systematic review and meta-analysis. Thyroid 201323 428-435. (doi:10.1089/thy.2012.0211)

8 Ghofrani M, Beckman D \& Rimm DL. The value of onsite adequacy assessment of thyroid fine-needle aspirations is a function of operator experience. Cancer 2006108 110-113. (doi:10.1002/cncr.21715)

9 O'Malley ME, Weir MM, Hahn PF, Misdraji J, Wood BJ \& Mueller PR. US-guided fine-needle aspiration biopsy of thyroid nodules: adequacy of cytologic material and procedure time with and without immediate cytologic analysis. Radiology 2002222 383-387. (doi:10.1148/radiol. 2222010201)

10 Raab SS, Grzybicki DM, Sudilovsky D, Balassanian R, Janosky JE \& Vrbin CM. Effectiveness of Toyota process redesign in reducing thyroid gland fine-needle aspiration error. American Journal of Clinical Pathology 2006126 585-592. (doi:10.1309/NJQ1L7KA10UKV93Q)

11 Redman R, Zalaznick H, Mazzaferri EL \& Massoll NA. The impact of assessing specimen adequacy and number of needle passes for fineneedle aspiration biopsy of thyroid nodules. Thyroid 200616 55-60. (doi:10.1089/thy.2006.16.55)

12 Zhu W \& Michael CW. How important is on-site adequacy assessment for thyroid FNA? An evaluation of 883 cases. Diagnostic Cytopathology 200735 183-186. (doi:10.1002/dc.20552)

13 Alexander EK, Heering JP, Benson CB, Frates MC, Doubilet PM, Cibas ES $\&$ Marqusee E. Assessment of nondiagnostic ultrasound-guided fine needle aspirations of thyroid nodules. Journal of Clinical Endocrinology and Metabolism 200287 4924-4927. (doi:10.1210/jc.2002-020865)

14 McHenry CR, Walfish PG \& Rosen IB. Non-diagnostic fine needle aspiration biopsy: a dilemma in management of nodular thyroid disease. American Surgeon 199359 415-419.

15 Chow LS, Gharib H, Goellner JR \& van Heerden JA. Nondiagnostic thyroid fine-needle aspiration cytology: management dilemmas. Thyroid 200111 1147-1151. (doi:10.1089/10507250152740993)

16 Welker L, Akkan R, Holz O, Schultz H \& Magnussen H. Diagnostic outcome of two different CT-guided fine needle biopsy procedures. Diagnostic Pathology 20072 31. (doi:10.1186/1746-1596-2-31)

17 Cibas ES \& Ali SZ. The Bethesda system for reporting thyroid cytopathology. Thyroid 200919 1159-1165. (doi:10.1089/thy. 2009.0274)

18 Amrikachi M, Ramzy I, Rubenfeld S \& Wheeler TM. Accuracy of fineneedle aspiration of thyroid. Archives of Pathology \& Laboratory Medicine 2001125 484-488.

19 Gharib H, Papini E, Paschke R, Duick DS, Valcavi R, Hagedüs L \& Vitti P American Association of Clinical Endocrinologists, Associazione Medici Endocrinologi, and European Thyroid Association medical guidelines for clinical practice for the diagnosis and management of thyroid nodules: executive summary of recommendations. Journal of Endocrinological Investigation 201033 (5 Suppl) 51-56. (doi:10.1007/ BF03346587)

20 Gharib H \& Papini E. Thyroid nodules: clinical importance, assessment, and treatment. Endocrinology and Metabolism Clinics of North America 200736 707-735, vi. (doi:10.1016/j.ecl.2007.04.009) 